\title{
Paraplegia
}

\section{Pressure Sore Carcinoma: A Late but Fulminant Complication of Pressure Sores in Spinal Cord Injury Patients: Case Reports*}

\author{
C. Dumurgier, ${ }^{1}$ G. Pujol, ${ }^{2}$ J. Chevalley, ${ }^{3}$ H. Bassoulet, ${ }^{4}$ E. Ucla, ${ }^{5}$ \\ P. Stchepinsky ${ }^{6}$ \\ ${ }^{1}$ Chirurgien en Chef, ${ }^{2}$ Anesthesiologiste, ${ }^{3}$ Anatomopathologiste, ${ }^{4}$ Chef du Service de \\ Radiotherapie, ${ }^{5}$ Chirurgien Assistant, ${ }^{6}$ Chirurgien Orthopediste, Service de Chirurgie et \\ de Paraplégies Traumatiques, Institution Nationale des Invalides, Paris 75007, \\ France.
}

\section{Summary}

The development of a pressure sore carcinoma in scars of spinal cord injury patients is a rare event (less than $0.5 \%$ ) and occurs late (more than 30 years after the spine injury) but the prognosis is very poor. Five cases are reported and different aspects are reviewed: anamnesis, clinical features, and follow-up studies. The association of surgery and radiotherapy is usual but is not very successful. Local-regional chemotherapy and a better approach concerning immunological mechanisms may improve survival. Scar prevention and surgical management of chronic scars treated unsuccessfully by medical methods are the best means to prevent malignant changes in chronic pressure sores. Biopsy should be mandotory for all pressure sores after the first decade.

Key words: Spinal cord injury; Pressure sores; Biopsies; Pressure sore carcinoma.

The Paraplegic Centre of the Institution Nationale des Invalides of Paris admits spinal cord injury (SCI) patients, who present with surgical complications, particulary those with pressure sores. ${ }^{9}$ More than 900 SCI patients have been followedup since 1955. ${ }^{1,13}$

Pressure sore carcinoma (also called under the eponym of Marjolin's ulcer ${ }^{18}$ threatens the life of SCI patients: 5 cases have been seen since 1979, 5 deaths within a mean period of 13 months, after the first positive biopsy.

After recording our cases and comparing them with other cases reported in the recent literature, $, 5,12,14$ we will try to give explanations for the high malignancy of these skin carcinomas, and their rapid evolution in spite of the treatment, before trying to find possible ways to improve the prognosis: Earlier diagnosis is possible thanks to systematic biopsies of every pressure sore after the first decade. We have studied the immunological profile. Because of the increase of the life expectancy of the SCI patients, pressure sore carcinoma may become more frequent.

*Presented at the 28th Annual Scientific Meetings of IMSOP, May 5 1989, Rome, Italy. 


\section{Case histories}

\section{Case 1}

A 50-year-old veteran with complete paraplegia since 1957 was transferred to the Service in June 1979 with a chronic sacral decubitus ulcer $(2 \times 3 \mathrm{~cm})$. Biopsy revealed an epidermoid carcinoma. In spite of surgery and radiotherapy, there were recurrencies (nodes) and the patient died in May 1980.

\section{Case 2}

A 54-year-old male with a 36 years' history of complete spastic paraplegia was admitted for a double location of pressure sores in August 1981. Biopsy showed a well differentiated epidermoid carcinoma. He died in June 1982, 9 months after the first positive biopsy.

\section{Case 3}

A 57-year-old veteran with a complete flaccid paraplegia for 36 years was admitted in May 1985 with a chronic trochanteric pressure sore. An epidermoid carcinoma was found. Eighteen months later, he was re-admitted with a large and profound recurrence, with leakage of urine. He died 6 weeks later.

\section{Case 4}

A 62-year-old Air Force Officer with a complete spastic paraplegia was admitted for a small sacral decubitus ulcer in November 1986. An epidermoid mature well differentiated carcinoma was found. Thirteen months later many inguinal nodes appeared (Fig. 1); but in spite of lymphadenomectomy, he died in July 1988.

\section{Case 5}

A 52-year-old veteran was wounded in 1959 and presented with an incomplete

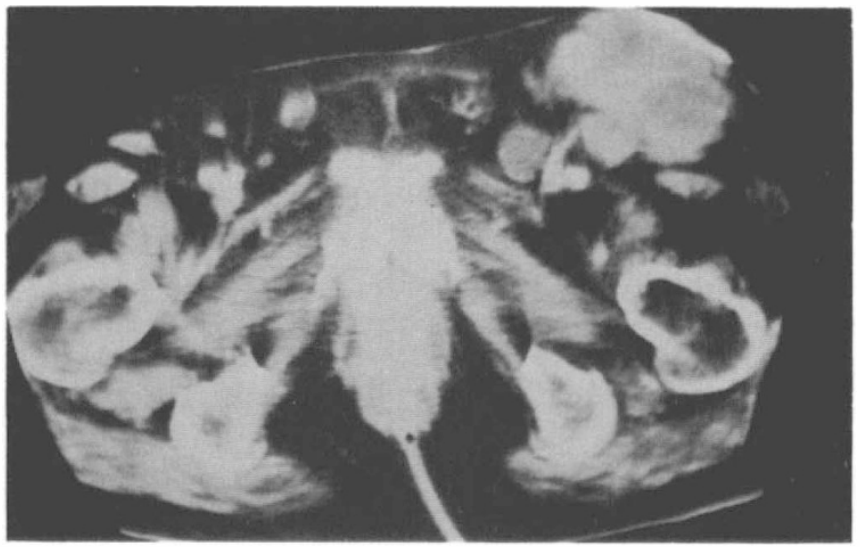

Figure 1 C.T. scan: Large inguinal lymph nodes (metastasis of a sacral pressure sore carcinoma). 


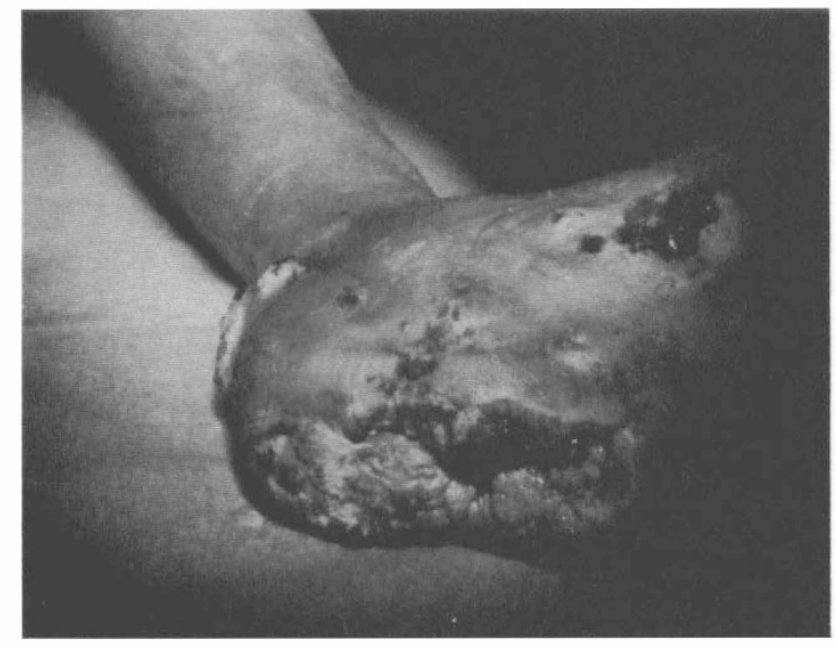

Figure 2 Typical cauliflower-like ulcer on the right heel, developed at the site of an old scar.

paraplegia with severe hypoesthesia of the right limb, there was no follow-up for 29 years. In April 1988, he was admitted with a large cauliflower-like ulcer of the right heel (Fig 2) and small lymphatic nodes in the right groin. An amputation of the thigh was performed with complete lymphadenomectomy. But 6 months later recurrences appeared around the stump and in spite of a complete iliectomy he died 3 months later.

\section{Results}

The mean age, when the 5 veterans were injured was 27 years.

Pressure sore carcinoma in SCI patients was evaluated by Mustoe and Coll ${ }^{14}$ at $0.5 \%$. This percentage will increase with the increased life expectancy of these patients.

The lesion levels were T4, T5, T12, L1, L5; complete peraplegia in 4 and partial in 1 patient. The primary treatment was a laminectomy in 4 patients, and Boehler's orthopedic treatment in 1 patient.

More interesting would be the study of trophic complications and management. Our 5 patients had pressure sores during the first year. Three have been followed for recurrences of pressure sores after the first discharge. They were treated by medical or surgical procedures in different hospitals. But 2 patients had no pressure sore for 30 years.

The mean interval between the injury and the first positive biopsy was 30 years (from 21-36 years). The location of the pressure ulcer was sacrum (3); heel (1) and trochanter (1).

The clinical features were not always typical; in three cases it was a velvety cauliflower-like growth on the surface of a long standing pressure sore; and in 2 patients it was a small decubitus ulcer.

All biopsies showed malignant transformation of the scar, a well differentiated squamous cell carcinoma, with the same histological aspects in the lymph nodes. 
Regional and general examination by plain X-rays and by CT scan revealed lymph node metastasis in two cases. The treatment was the same with a poor result: (a) surgery of the pressure sore; simple excision with biopsy, to amputation; and for the lymph nodes, régional lymphadenomectomy, (b) radiotherapy following the surgical procedure was given but was unsuccessful because of the poorly vascularised tissues of the extremities at the level of the lesion and (c) chemotherapy: the use of 5-FU was successful for certain Marjolin's ulcers, but not for the pressure sore carcinomas of SCI patients. ${ }^{17}$

\section{Discussion}

Pressure sore carcinoma, known under the eponym of Marjolin's ulcer is characterised by four features arising from a chronic pressure sore in SCI patients. There is a lag of three decades between injury and carcinoma as more than $80 \%$ die within 14 months.

Three questions remain without satisfying answers:

1. Why is there such a high mortality of Marjolin's ulcer in the SCI patient? The development of cancer in long-standing burn scars has been more often studied, ${ }^{7,}, 9$ as well as Marjolin's ulcers following osteomyelitis (11), fistulae (4) and cystostomy. (10) Studies also showed:

- Higher incidence of $2 \%$.

- Long lag for malignant change (32 years).

- Better prognosis: mortality about $32 \%$ after 5 years.

2. Why is pressure sore carcinoma such a highly lethal complication? Although we do not know the actual pathogenesis, ${ }^{3,6}$ the following factors play a role: (a) pressure sores in SCI patients are latent, usually indolent, and the diagnosis is always delayed; (b) the location of pressure sore carcinoma are the usual areas of hyperpressure (sacrum, ischium, trochanter) or on limbs i.e. tissues beneath the ulcer, with a complete modified lymph circulation; (c) the histological characters explain the failure of radiotherapy and chemotherapy according to the usual techniques; and (d) several authors ${ }^{2}{ }^{3}$ think that the malignant change is local for a long time, being within a scar. The tissues are surrounded by fibrosis thus it is an immunologically privileged tumour. But as soon as it extends beyond the scar, the evolution is fulminant. The disease is located regionally because of the lack of immunocompetence of tissues distal to the level of the spinal lesion, which are modified, polyoperated in most of the cases. The defence is overwhelmed.

3. How may the prognosis be improved? Thanks to the prevention of pressure sores: a better understanding of the mechanisms of scars allows a lower incidence of pressure sores among SCI patients in SCI units (30\%) whereas most of the SCI patients had scars in general hospitals, where they were admitted (at least for the first year).

With pressure sores the usual medical therapies are successful for most patients. If there is an early recurrence one must not be satisfied with limited healing. Even if the clinical aspect is not suspicious, a biopsy is mandatory after a wide excision followed by either direct suture or a flap coverage. The earlier the diagnosis is made, the better will be the effect of treatment.

Concerning pressure sore carcinoma:

(a) A study of the immunological profile will be done to evaluate defence: 
A

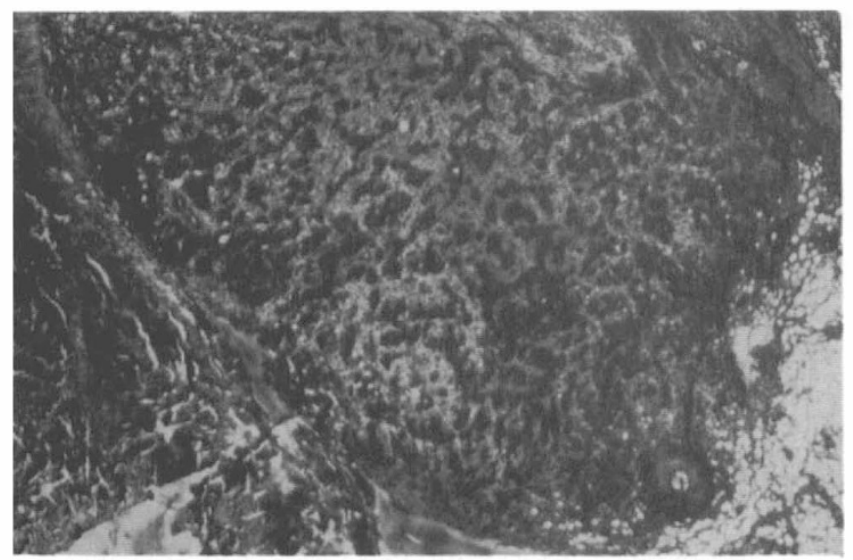

B

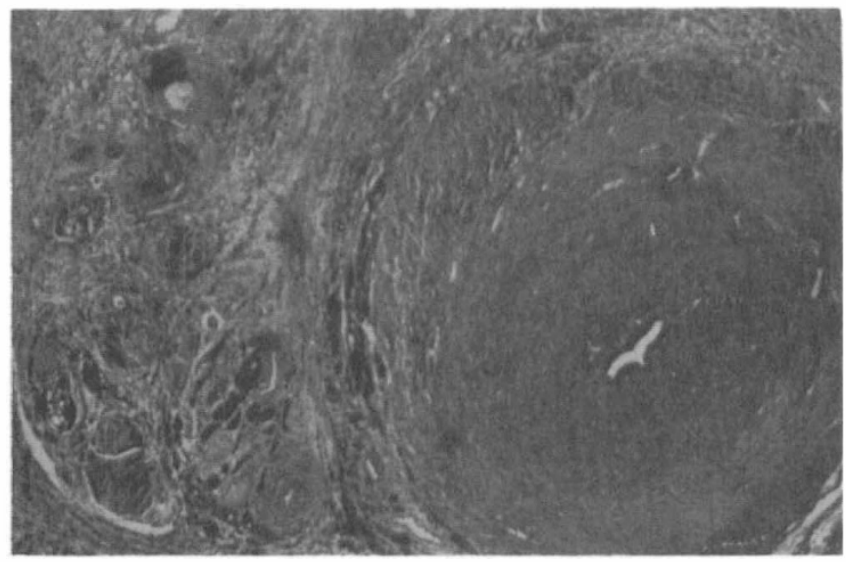

Figure 3 A: A completely-invaded lymph node by a metastasis of a pressure sore carcinoma of the right heel: mature and well differentiated epidermoïd carcinoma (x 25). B: Histological section of a lymphadenomectomy of the groin (x 35): Lymphatic extension of a mature well-differentiated carcinoma along the ductus deferens.

A study of the immunological profile of tissues is important regarding fibrosis and the number of lymphocytes:

(i) Antibodies anti T-cells

(ii) Immunoangioscintigraphy

(b) Treatment:

Aggressive surgery, ${ }^{16}$ if there are no lymph nodes; or surgery with regional chemotherapy ( 5 F.U. CIS platinium*) if the lymph nodes are invaded. (Fig. 3a and $3 b$ ).

Marjolin's ulcer is a serious threat for all SCI patients after two decades. We propose:

(1) Prevention of pressure sores in SCI patients

(2) Surgery for recurrent scars

(3) Systematic biopsy for all pressure sores-(mandatory after one decade of paraplegia). 


\section{References}

Avril G, Sibille P, Pujol G, Lagrave G 1988 La dégénérescence cancéreuse: une complication des escarres chez les paraplégiques et les tétraplégiques ( 3 cas). Annales de Chirurgie Plastique et Esthetique (Paris) 33:4:373-375.

BarR LH, MENARD JW 1983 Marjolin's ulcer Cancer 52:173-175.

Bostwick J, PENDERGRAST WJ, VasCONEZ LO 1976 Marjolin's ulcer: An immunologically privileged tumour? Plastic and Reconstructive Surgery 57:1:66-69.

Bowers RF, YOUNG JM 1960 Carcinoma arising in Scars, ostéomyelitis and fistulae. Archives of Surgery 80:564-570.

Casenave R 1979 A propos de deux cas d'épithélioma spinocellulullaire developpé sur escarre chez des paraplégiques. Thesis of Medicine (Paris)

Civatte J, Blanchet P 1976 Epithéliomas cutanés. Encycl. Med. Chir. Paris Dermatologie 12:750: A-10, A-20, A-30

Giblin T, Pickrell K, Pitts W, Armstrong D 1965 Malignant degeneration in burn scars. Annals of Surgery 163:2:291-297.

Grotting JC, Bunkis J, Vasconez LO 1987 Pressure sore carcinoma. Annals of Plastic Surgery 18:6: $527-532$.

GUTTMANN SIR LUDWIG 1973 Spinal cord injuries: comprehensive management and research. Blackwell Scientific Publications Chapter 30 494-496.

HOOPER AA, FORD HT 1973 Marjolin's ulcer complicating suprapubic cystostomy. British fournal Urology 45:534-535.

JOHNSON LL, KEMPSON RL 1965 Epidermoïd carcinoma in chronic osteomyelitis: diagnostic problems and management. Fournal of Bone and foint Surgery. 47:133.

Kimura T, ImaI G, Kaneco M 1969 Studies in classic decubitus ulcers after spinal injuries: Histological studies with four cases of decubitus cancer from sacral ulcers. IRVO 22:791-796.

Lagrave G, Bonis A, Renaud JP 1981 Le vieillissement. In: Paraplegie par M Maury: Flammarion Medicine Sciences Paris.

Mustoe T, Upton J, Marcellino V, Tun CJ, Rossier AB, Hachend HJ 1986 Carcinoma in chronic pressure sores: a fulminant disease process. Plastic and Reconstructive Surgery 77:(1):116-121.

Novick M, GARD DA, HARDY SB, SPIRA M 1977 Burn scar carcinoma: a review and analysis of 46 cases. Fournal of Trauma 17:(10):809-817.

Pearlman NW, McShane RH, Jochimsen Pr, Shirazi SS 1976 Hemicorporectomy for intractable decubitus ulcers. Archives of Surgery 111:1139.

RYAN RF, LITWIN MS, KREMENTZ ET 1981 A new concept in the management of Marjolin's ulcers. Annals of Surgery 193:(5):598-605.

STEFFEN C 1984 Marjolin's ulcer. American fournal of Dermatopathlogy 6:(2):187-193.

TrEves N, PACK GT 1930 The development of cancer in burn scars. Analysis and report of 34 cases. Surgery, Gynoecology and Obstetrics 51:749-782. 